University of Wollongong

Research Online

Faculty of Engineering and Information

Faculty of Engineering and Information

Sciences - Papers: Part A

Sciences

$1-1-2015$

\title{
Chemical cleaning effects on properties and separation efficiency of an RO membrane
}

Kha L. Tu

University of Wollongong, Ikt883@uowmail.edu.au

Allan R. Chivas

University of Wollongong, toschi@uow.edu.au

Long D. Nghiem

University of Wollongong, longn@uow.edu.au

Follow this and additional works at: https://ro.uow.edu.au/eispapers

Part of the Engineering Commons, and the Science and Technology Studies Commons

Research Online is the open access institutional repository for the University of Wollongong. For further information contact the UOW Library: research-pubs@uow.edu.au 


\title{
Chemical cleaning effects on properties and separation efficiency of an RO membrane
}

\author{
Abstract \\ This study aims to investigate the impacts of chemical cleaning on the performance of a reverse osmosis \\ membrane. Chemicals used for simulating membrane cleaning include a surfactant (sodium dodecyl \\ sulfate, SDS), a chelating agent (ethylenediaminetetraacetic acid, EDTA), and two proprietary cleaning \\ formulations namely MC3 and MC11. The impact of sequential exposure to multiple membrane cleaning \\ solutions was also examined. Water permeability and the rejection of boron and sodium were \\ investigated under various water fluxes, temperatures and feedwater $\mathrm{pH}$. Changes in the membrane \\ performance were systematically explained based on the changes in the charge density, hydrophobicity \\ and chemical structure of the membrane surface. The experimental results show that membrane cleaning \\ can significantly alter the hydrophobicity and water permeability of the membrane; however, its impacts \\ on the rejections of boron and sodium are marginal. Although the presence of surfactant or chelating \\ agent may cause decreases in the rejection, solution $\mathrm{pH}$ is the key factor responsible for the loss of \\ membrane separation and changes in the surface properties. The impact of solution $\mathrm{pH}$ on the water \\ permeability can be reversed by applying a subsequent cleaning with the opposite $\mathrm{pH}$ condition. \\ Nevertheless, the impacts of solution $\mathrm{pH}$ on boron and sodium rejections are irreversible in most cases.

\section{Disciplines} \\ Engineering | Science and Technology Studies

\section{Publication Details} \\ Tu, K. L., Chivas, A. R. \& Nghiem, L. D. (2015). Chemical cleaning effects on properties and seperation \\ efficiency of an RO membrane. Membrane Water Treatment, 6 (2), 141-160.
}




\title{
Chemical cleaning effects on properties and separation efficiency of an RO membrane
}

\author{
Kha L. Tu ${ }^{1}$, Allan R. Chivas ${ }^{2}$, Long D. Nghiem ${ }^{* 1}$ \\ ${ }^{1}$ Strategic Water Infrastructure Laboratory and GeoQuEST Research Centre, School of Civil, Mining, and \\ Environmental Engineering, University of Wollongong, NSW 2522, Australia \\ ${ }^{2}$ GeoQuEST Research Centre, School of Earth and Environmental Sciences, University of Wollongong, NSW \\ 2522, Australia
}

\begin{abstract}
This study aims to investigate the impacts of chemical cleaning on the performance of a reverse osmosis membrane. Chemicals used for simulating membrane cleaning include a surfactant (sodium dodecyl sulfate, SDS), a chelating agent (ethylenediaminetetraacetic acid, EDTA), and two proprietary cleaning formulations namely MC3 and MC11. The impact of sequential exposure to multiple membrane cleaning solutions was also examined. Water permeability and the rejection of boron and sodium were investigated under various water fluxes, temperatures and feedwater $\mathrm{pH}$. Changes in the membrane performance were systematically explained based on the changes in the charge density, hydrophobicity and chemical structure of the membrane surface. The experimental results show that membrane cleaning can significantly alter the hydrophobicity and water permeability of the membrane; however, its impacts on the rejections of boron and sodium are marginal. Although the presence of surfactant or chelating agent may cause decreases in the rejection, solution $\mathrm{pH}$ is the key factor responsible for the loss of membrane separation and changes in the surface properties. The impact of solution $\mathrm{pH}$ on the water permeability can be reversed by applying a subsequent cleaning with the opposite $\mathrm{pH}$ condition. Nevertheless, the impacts of solution $\mathrm{pH}$ on boron and sodium rejections are irreversible in most cases.
\end{abstract}

Keywords: boron; reverse osmosis (RO); membrane cleaning; sodium dodecyl sulfate (SDS), ethylenediaminetetraacetic acid (EDTA).

\section{Introduction}

Population growth and thriving economic development in recent decades are placing enormous pressure on the demand for freshwater supply. Water reclamation and desalination of seawater and brackish water have been recognised as key solutions to tackle the challenge of securing a reliable freshwater supply in many parts of the world (Elimelech and Phillip, 2011). Reverse osmosis (RO) is the most widely used technology for this purpose due to its efficiency and capacity to remove a wide range pollutants (Wintgens et al., 2005). The use of RO filtration is inherently associated with membrane fouling, which is the accumulation of colloidal particles, organic matter, inorganic salts and micro-organisms on the membrane surface. Indeed, membrane fouling can eventually occur in all membrane filtration applications regardless of pretreatment and any fouling control measures (Al-Amoudi and Lovitt, 2007; Fritzmann et al., 2007; Kaykioglu et al., 2012).

Membrane fouling leads to an increase in operating pressure and thus energy consumption. To recover the productivity of membrane installations, chemical cleaning is required. Chemicals

\footnotetext{
* Corresponding author, Associate Professor Long D. Nghiem, Email: longn@uow.edu.au
} 
typically used for membrane cleaning can be categorised as acidic (e.g. $\mathrm{HCl}$ and citric acid), caustic (e.g. $\mathrm{NaOH}$ and $\mathrm{KOH}$ ), surfactant (e.g. sodium dodecyl sulfate (SDS) and dodecyltrimethylammonium bromide (DTAB), metal chelating agent (e.g. ethylenediaminetetraacetic acid (EDTA)), and disinfectants (e.g. chloramine). Depending on the nature of the fouling layer, chemicals used for cleaning can be either acidic or caustic solution with some additives such as surfactants and/or metal chelating agents. The fouling layer usually comprises different types of foulant and each is best removed by a specific cleaning chemical. Thus, a complete cleaning process typically involves the use of various cleaning agents either simultaneously or sequentially. The use of SDS or EDTA in caustic condition has been recommended to improve cleaning efficiency ( $\mathrm{Li}$ et al., 2005; Liikanen et al., 2002). In addition, the combination of these two chemicals in caustic solution would be more efficient to mitigate membrane fouling than when each chemical is individually used (Madaeni et al., 2001). The frequency of the cleaning could range from a routine daily processes such as in whey processing to long-term annual processes such as in desalination plants according to the frequency and extent of fouling events (Van der Bruggen et al., 2003). However, the application of chemical cleaning should be limited to a minimum frequency since repeated chemical cleaning may affect the membrane performance and lifetime (Kimura et al., 2004). In fact, some studies reported that chemical cleaning can cause significant impacts on the membrane surface properties and thus affect the separation efficiency of the membrane.

Al-Amoudi (2013) reported that the nominal pore size of a nanofiltration (NF) membrane would be increased by more than $12 \%$ when the membrane was soaked in either a caustic SDS solution or a mixture of tri-sodium phosphate + sodium tri-polyphosphate + EDTA in $18 \mathrm{~h}$. The enlargement of the membrane pores resulted in an increase in water and solute permeability (i.e. rejection decreased). In contrast, the membrane pore size was not affected by acidic cleaning (with $\mathrm{HCl}$ (Al-Amoudi, 2013). Nevertheless, Simon et al. (2012) observed that the NF membrane pores could be enlarged by both strongly acidic (pH 1.5) and caustic ( $\mathrm{pH} 12)$ solutions. They suggested that both strongly acidic and caustic conditions caused an internal charged repulsion effect amongst charged groups in the membrane polymer matrix, leading to the expansion of the membrane structure (Simon et al., 2012). Some studies reported the decrease in salt rejection of membranes after caustic cleaning, however, such rejection loss can be recovered by applying an acidic cleaning subsequently (Liikanen et al., 2002; Madaeni and Samieirad, 2010). Chemical cleaning could also alter the membrane surface charge density and hydrophobicity. However, the impacts of such changes on the membrane separation appeared to be inconclusive and membranedependent (Al-Amoudi et al., 2007; Fujioka et al., 2013; Simon et al., 2012; Simon et al., 2013b; Tian et al., 2010). In fact, Simon et al. (2013a) reported that impacts of cleaning chemicals on the membrane performance depend on the thickness of the membrane active layer. Membranes with a thinner active layer would be more delicate to the impacts of cleaning chemicals. Fujioka et al. (2013) reported that chemical cleaning of RO membranes would affect the rejection of small and neutrally charged solutes such as N-nitrosodimethylamine (NDMA) at a higher magnitude than the rejection of hydrated salts such as sodium chloride. This result raised the concern of inadequate rejection of other small and neutrally charged pollutants such as boron by aged membranes. In fact, it has been reported that the rejections of NDMA and boron could be well correlated (Tu et al., 2013).

The impacts chemical cleaning, especially sequential cleaning, on the rejection of small and neutrally charged solutes by RO membranes have not been thoroughly understood. Thus, this study aims to investigate the effects of single and sequential membrane cleanings on boron rejection by RO membranes. Membrane cleaning agents used in this study include citric acid, sodium hydroxide, SDS, EDTA, a mixture of SDS+EDTA, and two commercial membrane cleaning formulations namely, MC3 and MC11. Changes in the water permeability and the 
rejections of boron and sodium are elucidated by any modifications in the membrane surface charge, hydrophobicity, and chemical composition.

\section{Materials and methods}

\subsection{Membranes and chemicals}

The low-pressure RO membrane ESPA2 (Hydranautics, Oceanside, CA) was used. This membrane is widely used for water reclamation for the removal of small and soluble organic contaminants as well as in the second pass of seawater desalination plants for boron removal. The manufacturer-recommended operational $\mathrm{pH}$ range of this membrane is from $\mathrm{pH} 2$ to 10.6. During chemical cleaning, a more aggressive $\mathrm{pH}$ range (i.e. from $\mathrm{pH} 1$ to $\mathrm{pH} 12$ ) can be used (Hydranautics, 2011). The ESPA2 is a thin-film composite membrane consisting of an ultra-thin polyamide skin layer on top of a micro-porous polysulfone support layer.

Analytical grade $\mathrm{NaCl}, \mathrm{CaCl}_{2}, \mathrm{NaHCO}_{3}$, and $\mathrm{B}(\mathrm{OH})_{3}$ (Ajax Finechem, Taren Point, NSW, Australia) were used to prepare the feed solution. Suprapur $\mathrm{HNO}_{3}$ (Merck Co., Darmstadt, Germany) was used for sample dilution prior to analysis. Milli-Q water (Millipore, Billerica, MA, USA) was used for the preparation of all stock and feed solutions. Chemicals used for simulating membrane cleaning include citric acid, sodium hydroxide, SDS, EDTA, a mixture of SDS and EDTA, and two proprietary membrane cleaning formulations namely MC3 and MC11 (IMCD, Mulgrave, Victoria, Australia). Properties of these solutions are presented in Table 1. EDTA and SDS solutions are prepared approximately five times more concentrated than the typically recommended values in order to accelerate any impact on the membrane. MC3 and MC11 solutions are used at the supplier-recommended concentration.

Table 1 Solution used for membrane cleaning simulation in this study.

\begin{tabular}{llll}
\hline Chemical/commercial name & Chemical formula/ingredient & Concentration & $\mathrm{pH}$ \\
\hline Citric acid (CA) & $\mathrm{C}_{6} \mathrm{H}_{8} \mathrm{O}_{7}$ & --- & 3 \\
\hline Sodium hydroxide (SH) & $\mathrm{NaOH}$ & --- & 11 \\
\hline Surfactant (SDS) & $\mathrm{NaC}_{12} \mathrm{H}_{25} \mathrm{SO}_{4}$ & $0.15 \%$ & 11 \\
\hline Chelating agent (EDTA) & $\mathrm{C}_{10} \mathrm{H}_{16} \mathrm{~N}_{2} \mathrm{O}_{8}$ & $5 \%$ & 11 \\
\hline $\begin{array}{l}\text { Mixture of surfactant and chelating } \\
\text { agent (SDS+EDTA) }\end{array}$ & & $0.15 \%$ SDS + 5\% & 11 \\
\hline MC3 & $\begin{array}{l}\text { Organic acid, detergent builders, and } \\
\text { chelating agents }\end{array}$ & 25 g.L $^{-1}$ & 3 \\
\hline MC11 & $\begin{array}{l}\text { pH buffer, detergent builders, and } \\
\text { chelating agents }\end{array}$ & 25 g.L $^{-1}$ & 11 \\
\hline
\end{tabular}

\subsection{Cross-flow membrane filtration system and experimental protocol}

A cross-flow membrane filtration system was utilised for evaluating the membrane performance. A detailed description of this system is available elsewhere (Tu et al., 2011). The cross-flow membrane cell has an active surface area of $40 \mathrm{~cm}^{2}(10 \mathrm{~cm} \times 4 \mathrm{~cm})$ with a channel height of $2 \mathrm{~mm}$.

At the beginning of each experiment, the membrane sample was compacted by using Milli-Q water at 30 bar for $18 \mathrm{~h}$. A stable flux was usually obtained within the first $10 \mathrm{~h}$ run. Following the membrane compaction, pure water permeability of the membrane was measured from 5 to 30 bar with 5 bar increments (at $20^{\circ} \mathrm{C}$ ). Electrolyte solution was then added to the feed reservoir making up a $10 \mathrm{~L}$ feedwater containing $10 \mathrm{mM} \mathrm{NaCl}, 1 \mathrm{mM} \mathrm{CaCl}_{2}, 1 \mathrm{mM} \mathrm{NaHCO}_{3}$, and $\left.0.43 \mathrm{mM} \mathrm{B(OH}\right)_{3}$ (or $4.6 \mathrm{mg} . \mathrm{L}^{-1} \mathrm{~B}$ ). Rejections were obtained at permeate fluxes of $10,20,42$, and $60 \mathrm{~L} \cdot \mathrm{m}^{-2} \cdot \mathrm{h}^{-1}$ (or 
$\mathrm{LMH}$ ), temperatures of $10,20,30$, and $40{ }^{\circ} \mathrm{C}$, and $\mathrm{pH}$ values of $7,8,9.5$, and 11 . Unless otherwise stated, the standard testing condition is $20 \mathrm{LMH}$ flux, $20^{\circ} \mathrm{C}, \mathrm{pH} 8$, and $42 \mathrm{~cm} \cdot \mathrm{s}^{-1}$ cross-flow velocity. The $\mathrm{pH}$ value was adjusted using either $1 \mathrm{M} \mathrm{NaOH}$ or $1 \mathrm{M} \mathrm{HCl}$ solution. In all experiments, once the target operational parameters had been obtained, the system was stabilised for $60 \mathrm{~min}$ before feed and permeate samples of $20 \mathrm{~mL}$ each were taken for analysis.

\subsection{Simulation of membrane cleaning}

Chemical cleaning was simulated by soaking flat-sheet virgin membrane samples in a sealed glass bottle containing a prepared cleaning solution for $25 \mathrm{~h}$. The bottle was immersed in a temperature-controlled water bath (SWB1, Stuart, Staffordshire, UK) and the temperature was maintained at $30 \pm 0.5^{\circ} \mathrm{C}$. The 25 -h exposure was chosen to simulate the cumulative membrane cleaning period over three years of operation. Similar simulated membrane cleaning protocol has been used elsewhere (Fujioka et al., 2013). After 25-h exposure to cleaning chemical, the membrane sample was removed from the solution and thoroughly rinsed with copious amount of Milli-Q water before being tested for surface properties and separation efficiency. Impacts of sequential cleaning on the membrane performance were investigated by soaking a virgin membrane in a cleaning solution for $25 \mathrm{~h}$ followed by another cleaning solution for $25 \mathrm{~h}$. The membrane was thoroughly rinsed with Milli-Q water between the two cleaning cycles.

The membrane cleaning protocol used in this study differs somewhat from that used in practice. Membrane cleaning in full-scale RO membrane plants usually includes circulations of cleaning solution which results in rigorous mixing of the solution to improve the cleaning efficiency. In addition, the fouling layer on a used membrane may partially shield the membrane from direct exposure to the cleaning agents. Despite these differences in the membrane cleaning regime, the protocol used in this study is probably the most appropriate for simulating the impacts of chemical cleaning under controlled conditions and has been widely used in other studies (Al-Amoudi et al., 2007; Fujioka et al., 2013; Simon et al., 2013b).

\subsection{Membrane characterisation methods}

The electro-kinetic property of the virgin and chemically cleaned membranes was measured using a SurPASS streaming potential analyser (Anton Paar GmbH, Graz, Austria). The zeta potential of the membrane surface was calculated from the measured streaming potential using the Fairbrother-Mastin approach (Childress and Elimelech, 1996). All streaming potential measurements were conducted in a background electrolyte solution containing $1 \mathrm{mM} \mathrm{KCl}$, at 500 mbar streaming pressure, and room temperature of approximately $25^{\circ} \mathrm{C}$. Analytical grade $\mathrm{HCl}$ and $\mathrm{KOH}$ were used to adjust the $\mathrm{pH}$ by means of automatic titration.

The hydrophobicity of the membrane surface was measured using a Rame-Hart goniometer (Model 250, Rame-Hart, Netcong, NJ) following the standard sessile drop method. Prior to each measurement, the membrane sample was dried in air for approximately $5 \mathrm{~h}$. Five Milli-Q water droplets were applied to each membrane sample and the contact angle was immediately measured on both sides of the droplet. Measurements were conducted at room temperature (ca. $25^{\circ} \mathrm{C}$ ).

FTIR analysis was conducted using a Shimadzu IRAffinity-1 (Kyoto, Japan) spectrometer to determine major functional groups of the virgin and chemically cleaned membranes. Membrane samples were placed on the ATR crystal and pressed onto the surface with a plate press. The measured spectrum was between $600 \mathrm{~cm}^{-1}$ and $1750 \mathrm{~cm}^{-1}$ at a resolution of $2 \mathrm{~cm}^{-1}$. Each scan was performed 20 times. Background correction was performed at the beginning of each measuring batch. 


\subsection{Analytical methods}

The concentrations of boron and sodium were analysed using an Agilent 7500cs inductivelycoupled plasma mass spectrometry (ICP-MS) system (Agilent Technologies, Wilmington, DE, USA). Concentrations of the ${ }^{11} \mathrm{~B}$ and ${ }^{23} \mathrm{Na}$ isotope were acquired and reported as the overall concentrations of boron and sodium. Detection limits for ${ }^{11} \mathrm{~B}$ and ${ }^{23} \mathrm{Na}$ were approximately 50 and 140 ng. $\mathrm{L}^{-1}$, respectively. Samples of the feedwater and permeate were diluted respectively 400 and 200 times using a $2 \%$ Suprapur $\mathrm{HNO}_{3}$ solution. Calibration and sensitivity tuning were conducted at the beginning of every analysis batch. Internal calibration was done using a Merck ICP multielement standard solution. The coefficient of determination $\left(R^{2}\right)$ for calibrations was greater than 0.99. The tuning was done using a multi-element tuning solution that contains $1 \mu \mathrm{g} . \mathrm{L}^{-1}$ of lithium, yttrium, cerium, thallium and cobalt. Each analysis was conducted in triplicate and the variation was found less than 5\%. Any instrumental drift during the analysis was corrected by analysing a 5 $\mu \mathrm{g} . \mathrm{L}^{-1}$ calibration standard every five samples.

Conductivity and $\mathrm{pH}$ were measured using an Orion 4-Star Plus $\mathrm{pH} /$ conductivity meter (Thermo Fisher Scientific, Beverly, MA).

Solute rejection was calculated using:

$\operatorname{Rej}(\%)=\frac{\mathrm{C}_{\mathrm{f}}-\mathrm{C}_{\mathrm{p}}}{\mathrm{C}_{\mathrm{f}}} \times 100$

Where $\mathrm{C}_{\mathrm{f}}$ and $\mathrm{C}_{\mathrm{p}}$ are the concentrations of solute in feedwater and permeate, respectively.

Changes in membrane performance (contact angle, water permeability) were calculated using:

Relative change $(\%)=\frac{X_{t r}-X_{v i r}}{X_{\text {vir }}} \times 100$

Where $\mathrm{X}_{\mathrm{tr}}$ and $\mathrm{X}_{\mathrm{vir}}$ are the performance parameters (i.e. contact angle or water permeability) of the cleaned membrane and virgin membrane, respectively.

\section{Results and discussions}

\subsection{Changes in the membrane surface properties}

\subsubsection{Charge density}

The charge density of a polymeric membrane surface may influence its pore structure and Donnan equilibrium which govern the rejection efficiency, particularly of charged solutes (Schaep et al., 2001). Charge density of the membrane was evaluated through the zeta potential value which indicates a net interaction between the membrane surface and an electrolyte (Hurwitz et al., 2010). In this study, the solution $\mathrm{pH}$ appeared to have a significant impact on the zeta potential of the ESPA2 membrane (Fig. 1). The influence of solution $\mathrm{pH}$ on the membrane zeta potential can be explained by the dissociation of functional groups on the membrane active layer (i.e. carboxylic and amine groups) (Childress and Elimelech, 1996). As the $\mathrm{pH}$ of the electrolyte increased from 3 to 11, the zeta potential of virgin ESPA2 membrane shifted from $+30 \mathrm{mV}$ to $-42 \mathrm{mV}$ with an isoelectric point at $\mathrm{pH} 4$ where minimum salt rejection and maximum water permeability is usually observed (Childress and Elimelech, 2000; Hoang et al., 2010; Teixeira et al., 2005). The 25-h acidic cleaning $(\mathrm{pH} 3)$ did not cause any considerable impact on the charge density of the ESPA2 membrane. On the other hand, the caustic cleaning $(\mathrm{pH} 11)$ made the membrane slightly more negatively charged at pH between 6 and 11 (Fig. 1). According to Elimelech et al. (1994), charged the profile of a membrane can be affected by the adsorption of ions on the membrane surface, which subsequently changes the dissociation of the membrane functional groups. 
The SDS cleaning resulted in a decrease in the charge density of the membrane surface over the entire $\mathrm{pH}$ range, both positive and negative charge (Fig. 1). It appeared that the SDS molecules were adsorbed on the membrane surface and inhibited the impact of $\mathrm{pH}$ on the dissociation groups of the membrane surface. Similar results have been reported by Simon et al. (2012); however, opposite results were observed by Al-Amoudi et al. (2007) who found that an over-night exposure to SDS would make the NF membranes more negatively charged from $\mathrm{pH} 3$ to 10 . The discrepancy may be attributed to the different conformations of the membranes used. The acidic cleaning conducted after SDS cleaning partially recovered the negative charge of the membrane (i.e. closer to the charge of virgin membrane) (Fig. 1). However, the isoelectric point was not recovered and was equal to that of the SDS-cleaned membrane. It is hypothesised that the association between SDS and membrane surface has been weakened by the citric acid solution. It is also noteworthy that there might be some modifications within the membrane pores but such changes could not be detected by the streaming potential measurement (Mänttäri et al., 2006). In fact, it was suggested that the charge within membrane pores, rather than that on the membrane surface, would have a significant impact on the separation efficiency of the membrane (Childress and Elimelech, 2000).

The impact of EDTA on the membrane charge was opposite to that of SDS cleaning, although these solutions had the same $\mathrm{pH}$ condition ( $\mathrm{pH} 11$ ). This result confirms that the membrane charge density is more significantly impacted by the surfactant or chelating agent rather than the $\mathrm{pH}$ of the cleaning solution. The zeta potential of the EDTA-cleaned membrane was slightly more negative than that of the virgin membrane (Fig. 1). The isoelectric point was also shifted to a lower $\mathrm{pH}$ value. The adsorption of EDTA on the membrane surface might have introduced more carboxylic groups on the membrane surface, and thus increased the negative charge of the membrane. The application of a subsequent acidic cleaning seemed not to considerably affect the membrane charge density (Fig. 1), which implies that EDTA molecules were still adsorbed on the membrane surface. At $\mathrm{pH}<5.5$, the zeta potential of the SDS+EDTA-cleaned membrane was comparable to that of those cleaned by either SDS or EDTA solution. However, at $\mathrm{pH}>5.5$, the zeta potential of the SDS+EDTA-cleaned membrane was equal to that of the virgin ESPA2 membrane (Fig. 1). It appeared that the charge density of the SDS+EDTA-cleaned membrane was the result of a neutralisation impact of individual cleaning agents. The mechanism of this effect has not been reported in the literature. The subsequent acidic cleaning led to a significant decrease in the negative charge of the SDS+EDTA-cleaned membrane (Fig. 1).

The formulated MC3 cleaning solution did not cause any considerable impact on the charge density of the ESPA2 membrane, whereas the MC11 solution led to a more negative membrane charge (Fig. 1). A similar result has been reported elsewhere (Fujioka et al., 2013). The subsequent caustic cleaning did not impact the charge of the MC3-cleaned membrane; however, it slightly decreased the negative charge of the MC11-cleaned membrane (Fig. 1). Since the exact composition of these solutions is proprietary, the mechanism of their impacts on the membrane charge cannot be elucidated. 


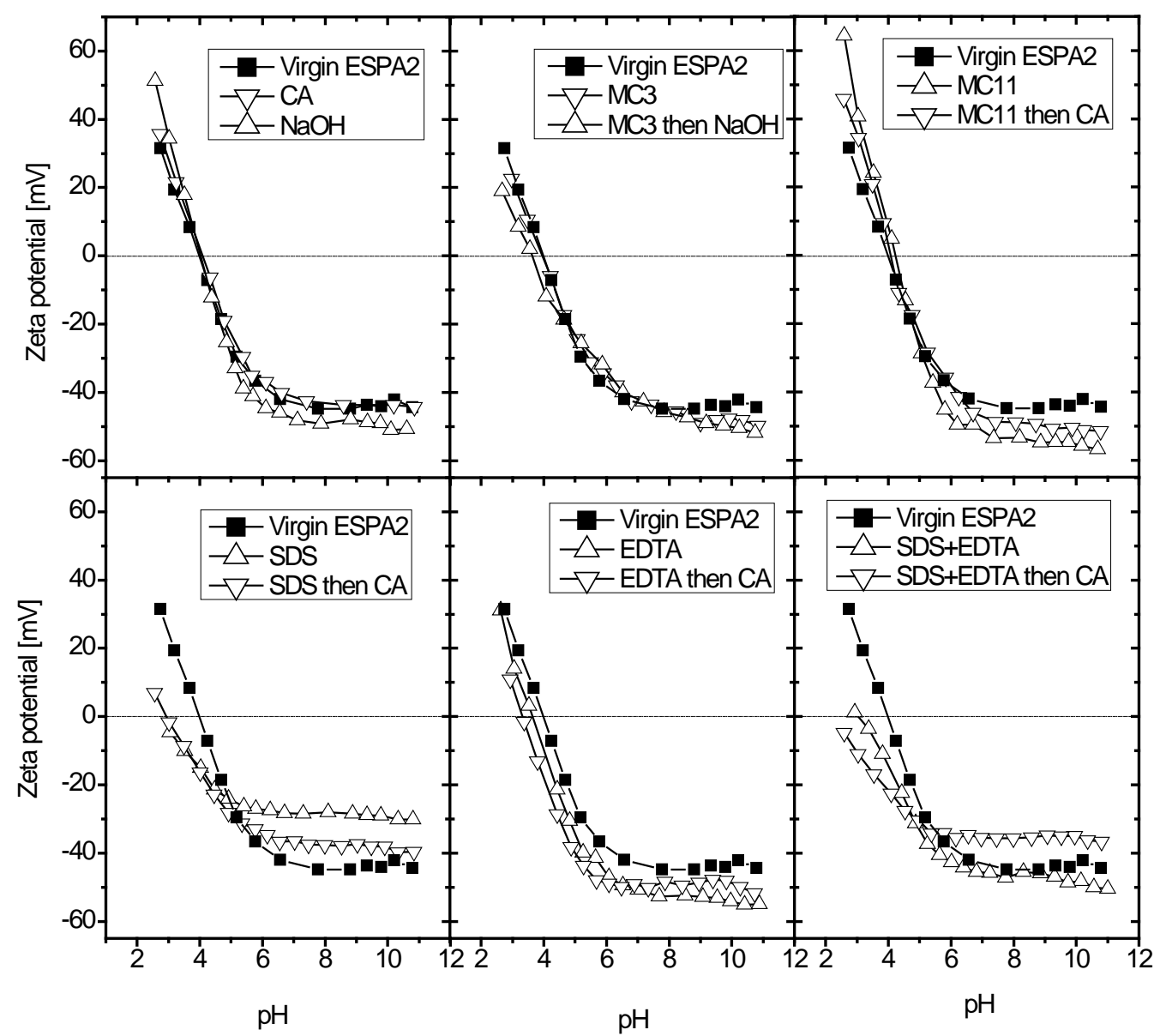

Fig. 1 Changes in zeta potential of the ESPA2 membrane as a consequence of single and sequential chemical cleaning. The measurements were conducted at room temperature (ca. $25^{\circ} \mathrm{C}$ ) in a $1 \mathrm{mM} \mathrm{KCl}$ solution.

\subsubsection{Hydrophobocity and surface bonding}

Chemical cleaning using either citric acid $(\mathrm{pH} 3)$ or sodium hydroxide $(\mathrm{pH} 11)$ rendered the ESPA2 membrane slightly more hydrophobic (Fig. 2). Similar results have been reported by Simon et al. (2012). Tian et al. (2010) hypothesised that sodium hydroxide could increase the membrane surface hydrophobicity by reacting with hydrophilic functional groups in the active layer. Previous studies (Hurwitz et al., 2010; Tang et al., 2009) showed that changes in the contact angle may indicate changes in the membrane conformation and also the charge density. However, in this study, no observable changes in the conformation of the membranes cleaned by either citric acid or sodium hydroxide can be seen from the zeta potential (Fig. 1) and FTIR (Fig. 3) measurements. On the other hand, chemical cleaning using either SDS or EDTA rendered the membrane more significantly hydrophilic (Fig. 2). These results are consistent with the literature, and could be attributed to the adsorption of hydrophilic SDS and EDTA molecules on the membrane polyamide structure (Ang et al., 2006; Simon et al., 2012; Weis et al., 2003). A study conducted by Kim et al. (2000) suggested that under extreme conditions, the polyamide active skin layer can be hydrolysed to carboxylic acid derivatives, resulting in an increase in surface hydrophilicity. Nevertheless, FTIR data (Fig. 3) do not show any hydrolysis of the membrane surface.

As expected, the mixture of SDS and EDTA increased the membrane's hydrophilicity (Fig. 2), 
given that these individual chemicals were found to cause the same effect. The formulated cleaning chemicals MC3 and MC11 shifted the membrane hydrophobicity in opposite directions. MC3 rendered the membrane more hydrophilic, whereas MC11 made it substantially more hydrophobic (Fig. 2). Similar results have been reported by Simon et al. (2013b). The high hydrophilicity of the MC3-cleaned membrane can be explained by the presence of hydrophilic chelating agents in the MC3 formula (Table 1). MC11 may contain hydrophobic ingredients but the specific formula is unidentified.

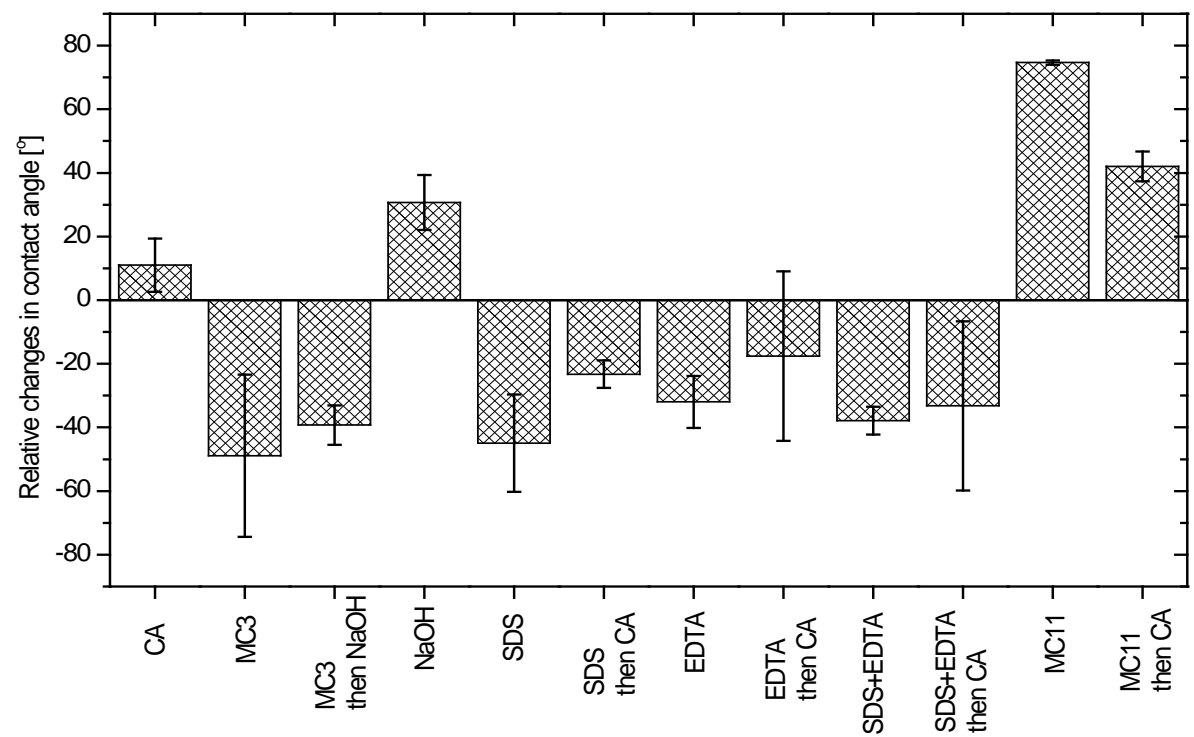

Fig. 2 Changes in contact angle values of the ESPA2 membrane as a consequence of single and sequential chemical cleaning. A positive value indicates an increase in the hydrophobicity, and vice versa. The measurements were conducted at room temperature (ca. $25^{\circ} \mathrm{C}$ ) with Milli-Q water used as a reference solvent. The error bars show the standard deviation of five replicated measurements.

It is interesting to note that the subsequent cleanings counteracted the impacts of the first cleaning chemical on the membrane hydrophobicity, and thus changes in the membrane hydrophobicity were diminished. A similar phenomenon with respect to the zeta potential of the chemically cleaned membranes could be observed in Fig. 1. Results reported here suggest the wash-out effect of the subsequent cleaning on the first one. Changes in the membrane hydrophobicity may result in changes in the membrane performance. For example, it was reported that a more hydrophilic membrane would have a higher water permeability (Akin and Temelli, 2011; Al-Amoudi et al., 2008) and a lower fouling propensity (Li et al., 2007). In addition, Bernstein et al. (2011) reported that a decrease in hydrophobicity would lead to a decrease in boron rejection, although the reason for such observation was not provided. 


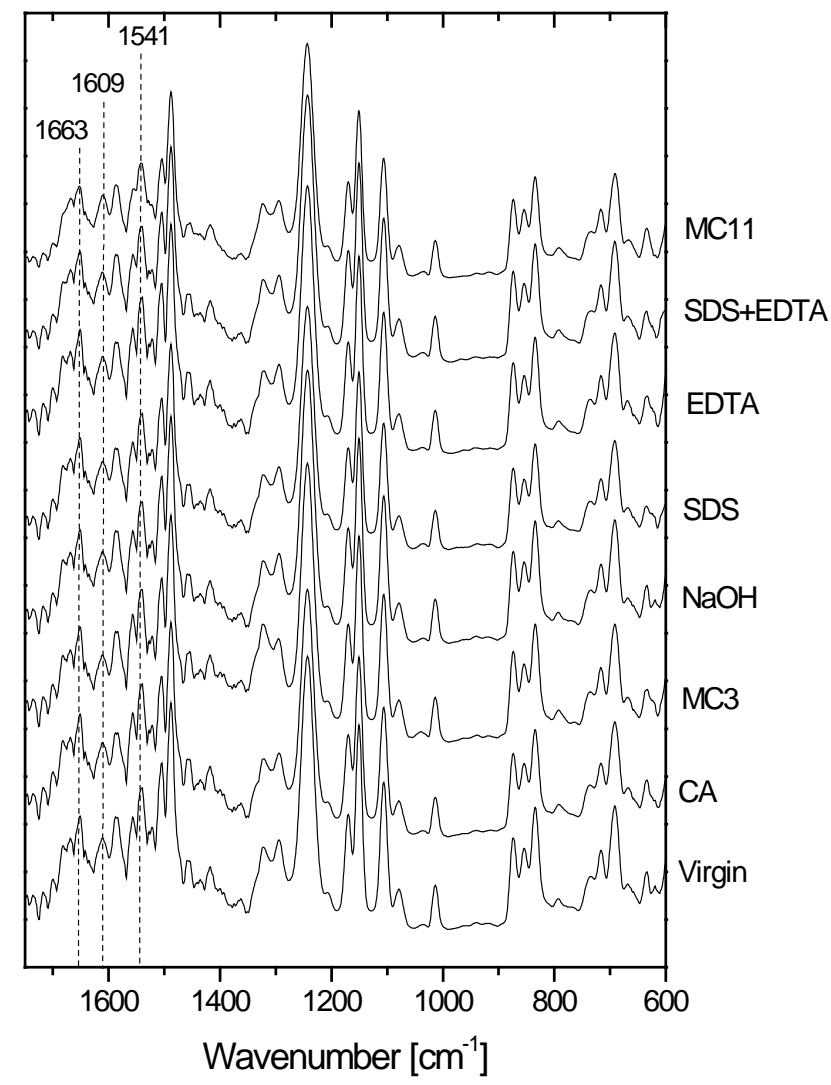

Fig. 3 FTIR absorption spectra of virgin and chemically cleaned ESPA2 membranes at $2 \mathrm{~cm}^{-1}$ resolution.

\subsection{Changes in membrane performance}

\subsubsection{Water permeability}

Previous studies have reported that the water permeability of NF/RO membranes would be either decreased or increased as a consequence of exposure to either strong acidic or caustic conditions, respectively (Al-Amoudi et al., 2007; Braghetta et al., 1997; Liikanen et al., 2002; Simon et al., 2012). Similar results were also found in this study. The 25-h acidic cleaning decreased the water permeability of the ESPA2 membrane by more than $10 \%$, whereas the caustic cleaning resulted in a 5\% water permeability increase (Fig. 4). Fundamental research conducted by Braghetta et al. (1997) attributed the increase in the water permeability of NF membranes in caustic conditions to the enhanced internal electrostatic charged repulsion within the membrane matrix which increased the membrane porosity and so the water permeability. This explanation is supported by the increase in charge density of the $\mathrm{NaOH}$-cleaned membrane as observed in Fig. 1. Interestingly, Childress and Elimelech (2000) reported that the pore size of membranes would be reduced at both low and high $\mathrm{pH}$, which resulted in the decrease in water permeability in both acidic and caustic conditions. Considering the above discrepant results, the impact of $\mathrm{pH}$ on the membrane water permeability seems to be membrane-dependent.

The 25-h membrane cleaning using either SDS or EDTA in caustic conditions resulted in a significant increase (ca. 15\%) in the water permeability of the ESPA2 membrane. A similar result has been reported in the literature (Al-Amoudi et al., 2007; Li and Elimelech, 2004; Simon et al., 2012), and was attributed to the adsorption of SDS or EDTA molecules on the membrane surface. The adsorption of these hydrophilic agents renders the membrane surface more hydrophilic thus 
leads to an increase in its water permeability. This explanation is supported by the increase in the hydrophilicity of the SDS-cleaned membrane and the EDTA-cleaned membrane as observed in Fig. 2. In addition, Liikanen et al. (2002) suggested that at high $\mathrm{pH}$, EDTA could complex with some membrane constituents, resulting in an increase in the membrane porosity and so an increase in the water permeability. As expected, the mixture of SDS and EDTA in caustic conditions increased the water permeability of the cleaned membrane (Fig. 4). It is interesting to note that the correlation between increased hydrophilicity and increased water permeability was not seen with the formulated cleaning chemicals MC3 and MC11. The MC3-cleaned membrane and MC11cleaned membrane obtained lower and higher water permeability, respectively (Fig. 4), even though the MC3-cleaned membrane was very hydrophilic and the MC11-cleaned membrane was highly hydrophobic (Fig. 2). Similar results were reported by Simon et al. (2013b). However, this phenomenon cannot be thoroughly explained since the exact compositions of these two commercially available formulated chemical cleaning solutions are not known.

It is noteworthy that the impacts of the chemical cleaning on the water permeability, either positive or negative, can be mitigated or even inverted by applying a subsequent cleaning step with a $\mathrm{pH}$ condition opposite to that of the initial cleaning solution. For example, cleaning with MC3 in acidic conditions decreased $6 \%$ of the water permeability of the virgin membrane, and the subsequent caustic cleaning led to a $25 \%$ increase in water permeability compared to the virgin membrane (Fig. 4). A similar observation was reported by Fujioka et al. (2013). It appears that the $\mathrm{pH}$ of the cleaning solutions has a strong impact on the water permeability of the membrane.

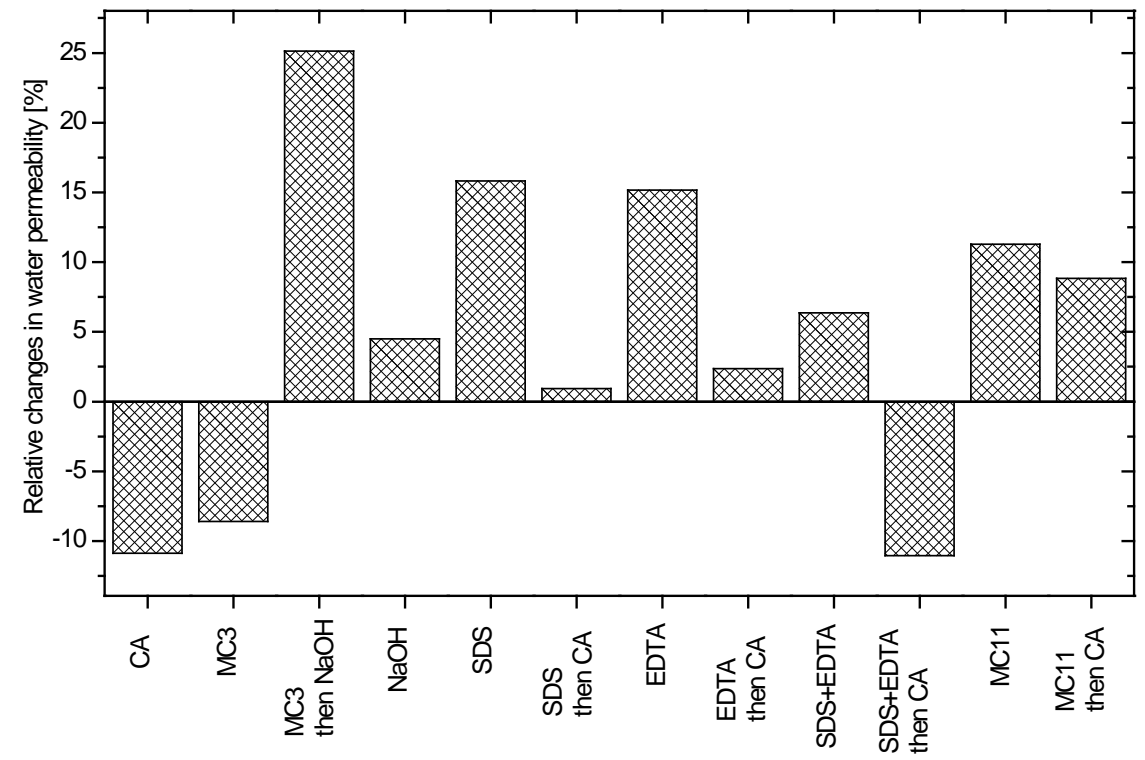

Fig. 4 Relative change in the water permeability of ESPA2 membranes as a consequence of single and sequential chemical cleaning. The water permeability was measured with Milli-Q water from 5 to 30 bar with 5 bar increments and at $20^{\circ} \mathrm{C}$; cross-flow velocity $42 \mathrm{~cm} \cdot \mathrm{s}^{-1}$.

\subsubsection{The rejection of boron and sodium}

Membrane cleaning solutions usually contain surfactant and chelating agents in either caustic or acidic condition. For a systematic investigation of the impacts of membrane cleaning on the membrane integrity, the impacts of caustic and acidic conditions are first examined in this study. The rejections of boron and sodium by virgin and cleaned membranes were investigated as functions of permeate flux, temperature, and solution $\mathrm{pH}$. In good agreement with the literature (Hung et al., 2009; Koseoglu et al., 2008), boron rejection was strongly affected by flux, 
temperature and feed solution $\mathrm{pH}$. Boron rejection by the virgin ESPA2 varied from 45 to $72 \%$ when the permeate flux increased from 10 to $60 \mathrm{LMH}$. Similarly, the increase in water temperature from 10 to $40{ }^{\circ} \mathrm{C}$ caused a decrease in boron rejection from 69 to $40 \%$ (Fig. 5). In particular, boron rejection by the virgin ESPA2 reached $90 \%$ at the water $\mathrm{pH}$ of 11 . On the other hand, sodium rejection was higher than $95 \%$ and marginally affected by the operating condition changes (Fig. 5). Transport mechanisms and the impacts of flux, temperature and $\mathrm{pH}$ on boron and sodium rejection have been well discussed in the literature (Ben Amar et al., 2009; Kezia et al., 2013). Possessing a $\mathrm{pK}_{\mathrm{a}}$ of 9.2, the boric acid molecule is poorly hydrated in aqueous solutions having a $\mathrm{pH}$ lower than this value. Boron rejection by commercial RO membranes is relatively low because the boric acid molecule is small in size (its Stokes radius is approximately double that of the water molecule) and neutrally charged. The transformation from boric acid to borate species explains the increase in boron rejection as the $\mathrm{pH}$ increased (Tu et al., 2011). On the other hand, being a hydrated and charged species at all $\mathrm{pH}$ values, the sodium ion can be efficiently removed by a RO membrane regardless of operating condition changes (Tu et al., 2011).

Several studies have been dedicated to investigate the impacts of acidic and caustic cleaning on the separation efficiency of NF/RO membranes. Although using different membranes and different targeted solutes, there is a good agreement amongst studies that caustic cleaning would markedly decrease the rejection efficiency of the membranes, whereas acidic cleaning did not cause any considerable impacts. Caustic cleaning was reported to decrease the rejection of NDMA (Fujioka et al., 2013), $\mathrm{MgCl}_{2}$ (Al-Amoudi, 2013) and carbamazepine (Simon et al., 2012) by various $\mathrm{NF} / \mathrm{RO}$ membranes. In this study, the 25-h caustic cleaning with sodium hydroxide (pH 11) resulted in an approximately $10 \%$ decrease in boron rejection, whereas sodium rejection was unaffected (Fig. 5). The boron rejection loss was consistently observed at various testing permeate fluxes, temperatures, and $\mathrm{pH}$ values, which indicated that the changes were caused by the modification of the membrane surface. In practice, caustic cleaning is a typical membrane cleaning procedure because it is very useful to remove many types of foulant (Ang et al., 2006; Li and Elimelech, 2004). The loss of boron rejection efficiency as seen on Fig. 5 may raise major concerns of inadequate boron level in permeate water produced by aged membrane installations. The decrease in boron rejection, together with the increase in water permeability (Fig. 4) of the caustic-cleaned membrane, can be attributed to an increase in the membrane porosity which is caused by an increased internal charged repulsion (Braghetta et al., 1997). Sodium rejection is unaffected by this mechanism because the increased internal charged repulsion would help to sustain or even improve the rejection of hydrated sodium molecules in the solution (Braghetta et al., 1997).

Acidic cleaning was reported to cause negligible impacts on the rejection of NDMA (Fujioka et al., 2013) and $\mathrm{MgCl}_{2}$ (Al-Amoudi, 2013) by NF/RO membranes. In this study, the 25-h acidic cleaning with citric acid $(\mathrm{pH} 3)$ led to an approximate $10 \%$ decrease in boron rejection and $5 \%$ decrease in sodium rejection (Fig. 5). This rejection loss indicates major conformational changes occurred within the membrane polymer structure. It is noteworthy that such rejection decrease was coupled with a $10 \%$ decrease in water permeability of the acidic-cleaned membrane (Fig. 4). The concurrent loss of water permeability and solute rejection was reported elsewhere in the literature (Kang et al., 2007), and was attributed to the transformation from crystalline regions to an amorphous state of the membrane polymer structure. According to Kang et al. (2007), this transformation led to a cleavage of the polyamide structure which decreased solute rejection and created a "soft barrier layer" which was compacted under operating pressure and consequently resulted in a flux decline. However, FTIR analysis in this study is not adequately sensitive to detect these changes (Fig. 3) and thus the exact mechanisms accounting for this phenomenon cannot be verified. 


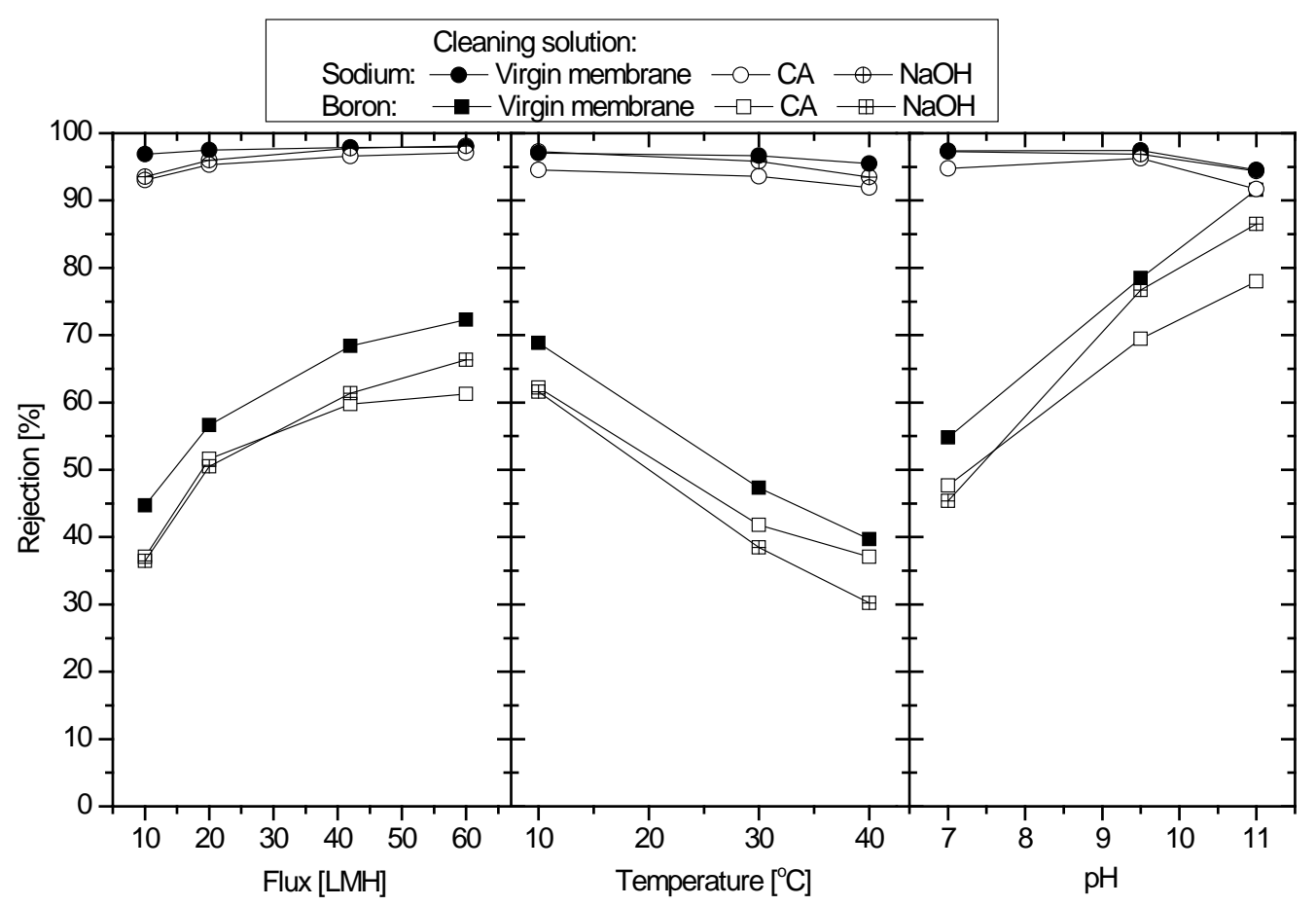

Fig. 5 Changes in boron and sodium rejections by the ESPA2 membrane as a consequence of acidic (citric acid, CA) or caustic $(\mathrm{NaOH})$ cleaning. Unless otherwise stated, the testing conditions are: $\mathrm{pH} 8$, feedwater contains $0.43 \mathrm{mM} \mathrm{B}(\mathrm{OH})_{3}, 10 \mathrm{mM} \mathrm{NaCl}, 1 \mathrm{mM} \mathrm{NaHCO}_{3}$, and $1 \mathrm{mM} \mathrm{CaCl}_{2}$; temperature 20 ${ }^{\circ} \mathrm{C}$, permeate flux $20 \mathrm{LMH}$, cross-flow velocity $42 \mathrm{~cm} . \mathrm{s}^{-1}$.

The reported results regarding the impacts of SDS cleaning on the membrane performance are discrepant and appear to be strongly membrane-dependent (Al-Amoudi, 2013; Childress and Elimelech, 2000; Simon et al., 2013a). In this study, the rejections of boron and sodium by the SDS-cleaned membrane were comparable to that by the $\mathrm{NaOH}$-cleaned membrane (Fig. 6). This result implies that SDS itself does not cause any negative impact on the rejection efficiency of the membrane. The SDS-cleaned membrane had a lower boron and sodium rejection than the virgin ESPA2 membrane because of the caustic condition as discussed previously (Fig. 5). The application of an acidic cleaning after SDS cleaning caused a substantial decrease in sodium rejection and sustained the boron rejection of the cleaned membrane (Fig. 6). This phenomenon has not been reported in the literature. As previously discussed, the application of citric acid could remove the adsorbed SDS from the membrane surface. It is hypothesised that this process also changes the internal pore structure of the membrane, likely the charge within pores which is not detected by the streaming potential measurement. The decrease in sodium rejection is a result of the decrease in charged repulsion between sodium molecules and internal membrane pores. 


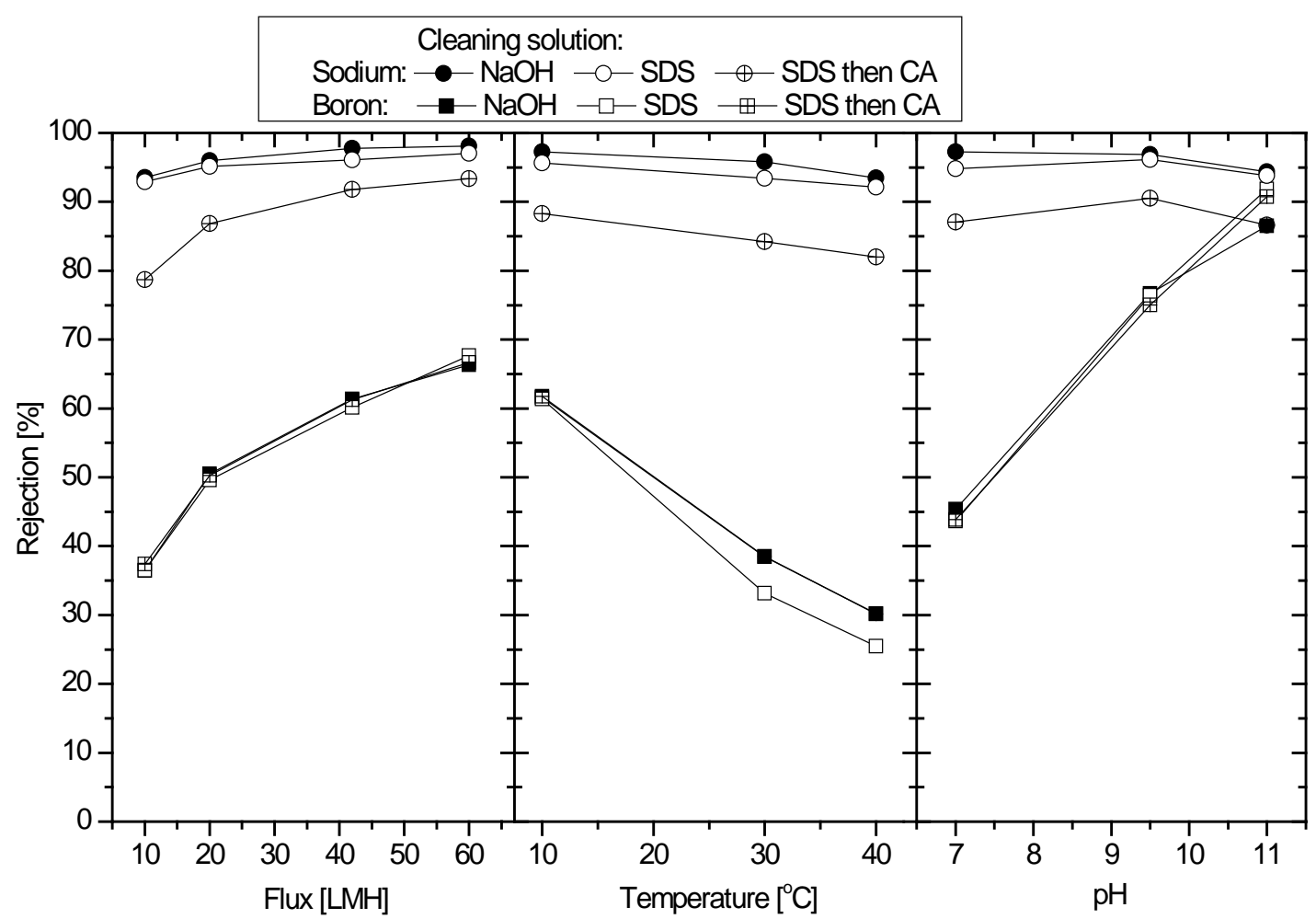

Fig. 6 Changes in boron and sodium rejections by the ESPA2 membrane after membrane cleaning with SDS solution ( $\mathrm{pH} 11)$ and SDS solution followed by citric acid solution ( $\mathrm{pH} 3)$. Unless otherwise stated, the testing conditions are: $\mathrm{pH}$, feedwater contains $0.43 \mathrm{mM} \mathrm{B}(\mathrm{OH})_{3}, 10 \mathrm{mM} \mathrm{NaCl}, 1 \mathrm{mM} \mathrm{NaHCO}$, and 1 $\mathrm{mM} \mathrm{CaCl}_{2}$; temperature $20{ }^{\circ} \mathrm{C}$, permeate flux $20 \mathrm{LMH}$, cross-flow velocity $42 \mathrm{~cm} . \mathrm{s}^{-1}$.

Compared to the $\mathrm{NaOH}$-cleaned membrane, the EDTA-cleaned membrane obtained a marginally lower sodium rejection (i.e. 5\% lower) and a comparable boron rejection (Fig. 7). This result is consistent with previous studies (Simon et al., 2013a; Simon et al., 2012) which found that EDTA cleaning in caustic conditions does not cause considerable impact on the separation efficiency of membranes. However, in contrast with SDS, the application of an acidic cleaning after EDTA cleaning recovered the rejection of sodium to the level of the $\mathrm{NaOH}$-cleaned membrane (Fig. 7). It is noteworthy that this sodium rejection was still lower than that by the virgin membrane. Consistent with the surface analysis results (i.e. charge and hydrophobicity), it appears that the adsorbed EDTA on the membrane surface has been removed by the acidic cleaning and this process does not negatively affect the membrane polymer structure. 


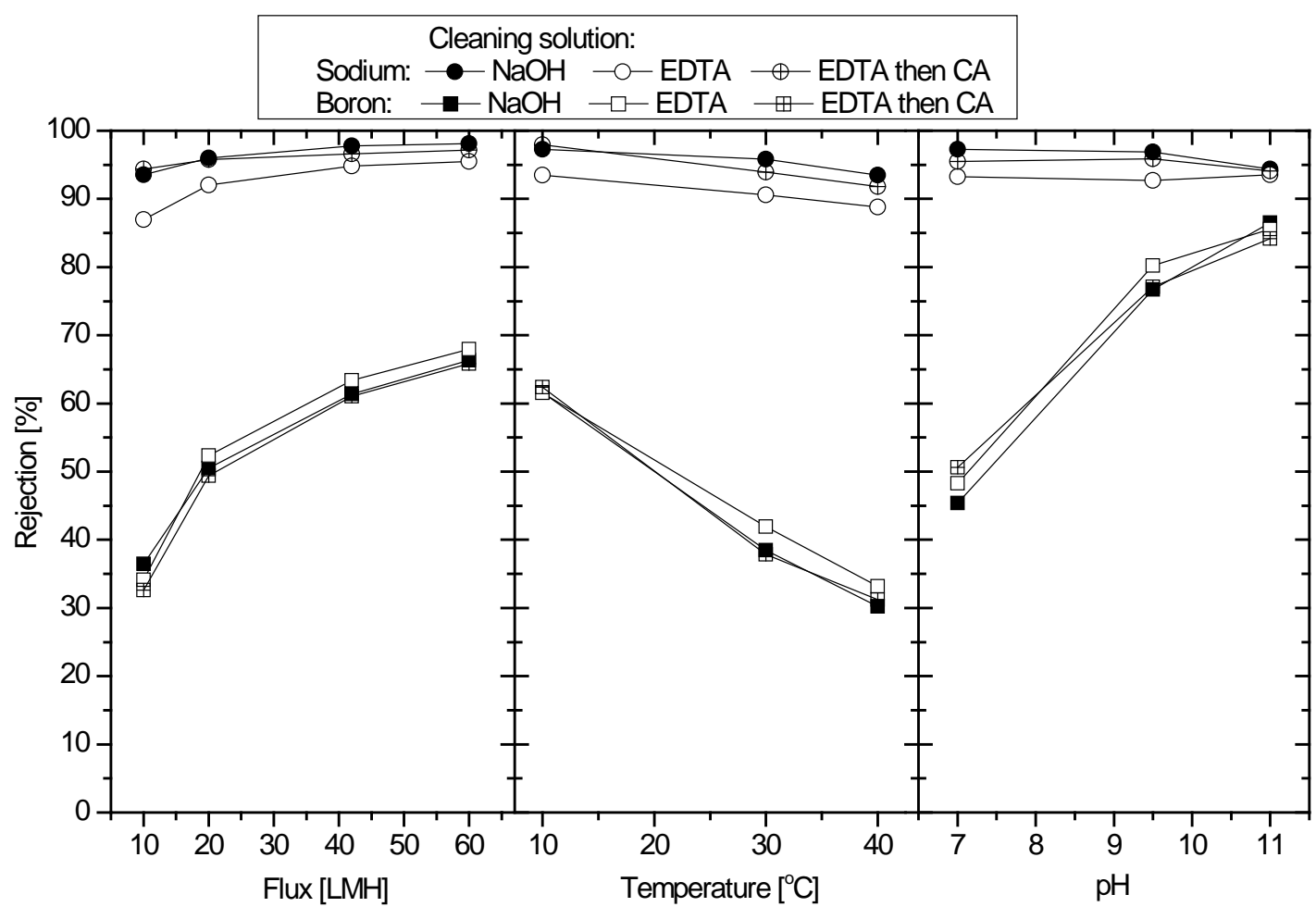

Fig. 7 Changes in boron and sodium rejections by the ESPA2 membrane after membrane cleaning with EDTA solution ( $\mathrm{pH} 11$ ) and EDTA solution followed by citric acid solution ( $\mathrm{pH} \mathrm{3).} \mathrm{Unless} \mathrm{otherwise}$ stated, the testing conditions are: $\mathrm{pH} 8$, feedwater contains $0.43 \mathrm{mM} \mathrm{B}(\mathrm{OH})_{3}, 10 \mathrm{mM} \mathrm{NaCl}, 1 \mathrm{mM}$ $\mathrm{NaHCO}_{3}$, and $1 \mathrm{mM} \mathrm{CaCl}_{2}$; temperature $20^{\circ} \mathrm{C}$, permeate flux $20 \mathrm{LMH}$, cross-flow velocity $42 \mathrm{~cm} . \mathrm{s}^{-1}$. Impacts of the combined SDS and EDTA in a caustic solution on the membrane performance have not been reported in the literature, although this mixture was found to be more effective to mitigate membrane fouling than individually used (Madaeni et al., 2001). In this study, the SDS+EDTA-cleaned membrane had approximately 8\% lower boron rejection than the causticcleaned membrane (Fig. 8), and consequently about 18\% lower than that of the virgin membrane (Figs. 5 and 8). Sodium rejection appeared to be unaffected by the SDS+EDTA cleaning solution (Fig. 8). This impact is different from that caused by separated SDS cleaning and EDTA cleaning, which implies that there probably are mutual interactions amongst SDS, EDTA, and the membrane surface when SDS and EDTA are used simultaneously. Because boron rejection is mainly governed by the sieving effect, the decrease in boron rejection indicates an increase in the pore size of the SDS+EDTA-cleaned membrane. Nevertheless, this expansion of the membrane pores appears to be retreated when an acidic cleaning was subsequently applied, indicating through the recovery of boron rejection (Fig. 8). However, the application of acidic cleaning could not recover the boron rejection by the SDS+EDTA-cleaned membrane back to level of the virgin membrane (Fig. 5 and 8). 


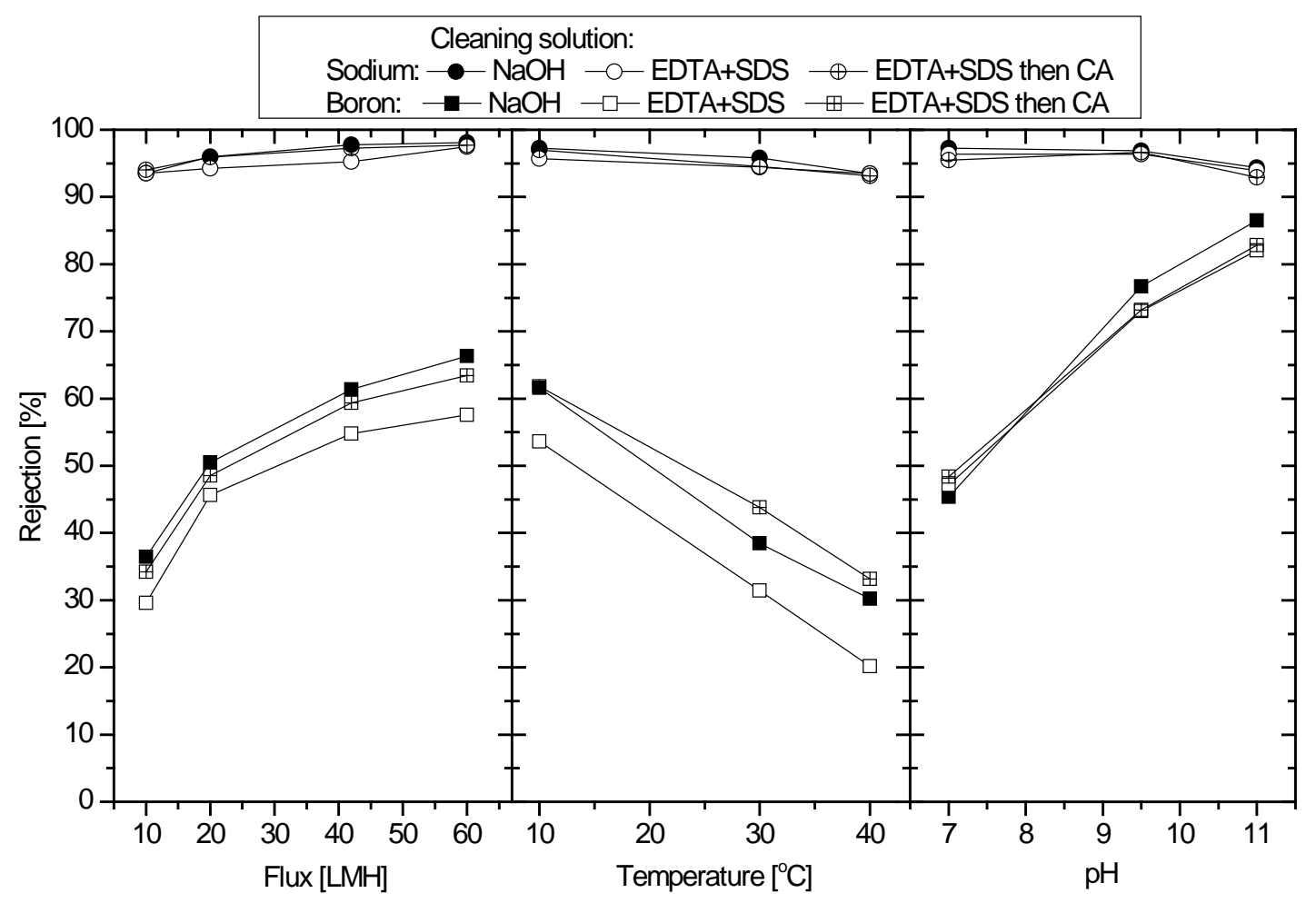

Fig. 8 Changes in boron and sodium rejections by the ESPA2 membrane after membrane cleaning with EDTA+SDS solution ( $\mathrm{pH} \mathrm{11)} \mathrm{and} \mathrm{EDTA+SDS} \mathrm{solution} \mathrm{followed} \mathrm{by} \mathrm{citric} \mathrm{acid} \mathrm{solution} \mathrm{(pH} \mathrm{3).} \mathrm{Unless}$ otherwise stated, the testing conditions are: $\mathrm{pH}$ 8, feedwater contains $0.43 \mathrm{mM} \mathrm{B}(\mathrm{OH})_{3}, 10 \mathrm{mM} \mathrm{NaCl}, 1$ $\mathrm{mM} \mathrm{NaHCO}_{3}$, and $1 \mathrm{mM} \mathrm{CaCl}_{2}$; temperature $20^{\circ} \mathrm{C}$, permeate flux $20 \mathrm{LMH}$, cross-flow velocity $42 \mathrm{~cm} . \mathrm{s}^{-}$ 1

Boron rejection by the MC11-cleaned membrane was comparable to that of the caustic cleaned membrane (Fig. 9), which was approximately 10\% lower than boron rejection of the virgin membrane (Fig. 5). A similar result was reported by Fujioka et al. (2013) who found that the rejection of NDMA - a compound having similar molecular property to boron, would be decreased when the ESPA2 membrane was cleaned by MC11. In good agreement with a previous study result (Simon et al., 2013b), the rejection of sodium by the MC11-cleaned membrane was equivalent to that of the caustic-cleaned and also of the virgin ESPA2 (Fig. 5 and 9). The acidic cleaning following the MC11 cleaning did not cause any impacts on boron and sodium rejection, and thus a 10\% lower boron rejection than the virgin membrane still remained (Fig. 5 and 9). 


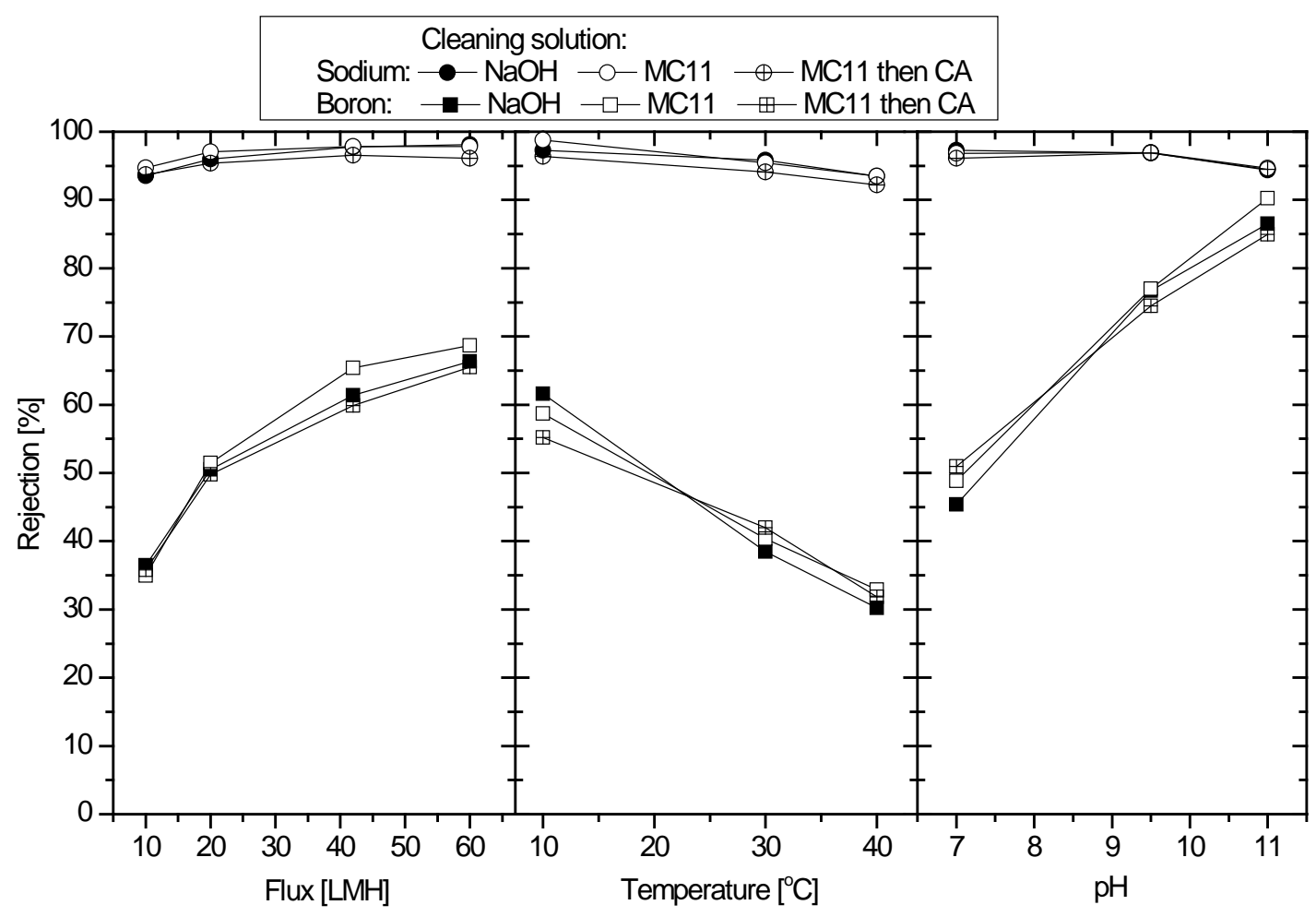

Fig. 9 Changes in boron and sodium rejections by the ESPA2 membrane after membrane cleaning with MC11 solution ( $\mathrm{pH} 11$ ) and MC11 solution followed by citric acid solution ( $\mathrm{pH} 3$ ). Unless otherwise stated, the testing conditions are: $\mathrm{pH} 8$, feedwater contains $0.43 \mathrm{mM} \mathrm{B}(\mathrm{OH})_{3}, 10 \mathrm{mM} \mathrm{NaCl}, 1 \mathrm{mM}$ $\mathrm{NaHCO}_{3}$, and $1 \mathrm{mM} \mathrm{CaCl}_{2}$; temperature $20^{\circ} \mathrm{C}$, permeate flux $20 \mathrm{LMH}$, cross-flow velocity $42 \mathrm{~cm} . \mathrm{s}^{-1}$.

Interestingly, MC3 appeared to be the only cleaning chemical tested in this study which could recover the decreased boron rejection caused by acidic/caustic solutions, thus preserved boron and sodium rejections of the cleaned membrane as high as that of the virgin membrane (less than $5 \%$ variation) (Fig. 5 and 10). In other studies, membrane cleaning using MC3 was found to cause discernable impacts on the rejections of organic compounds and inorganic salts (Fujioka et al., 2013; Simon et al., 2013b). The application of a caustic cleaning after the MC3 cleaning did not cause any impacts on the rejections (Fig. 10) although this cleaning process causes major changes on the membrane water permeability (Fig. 4). 


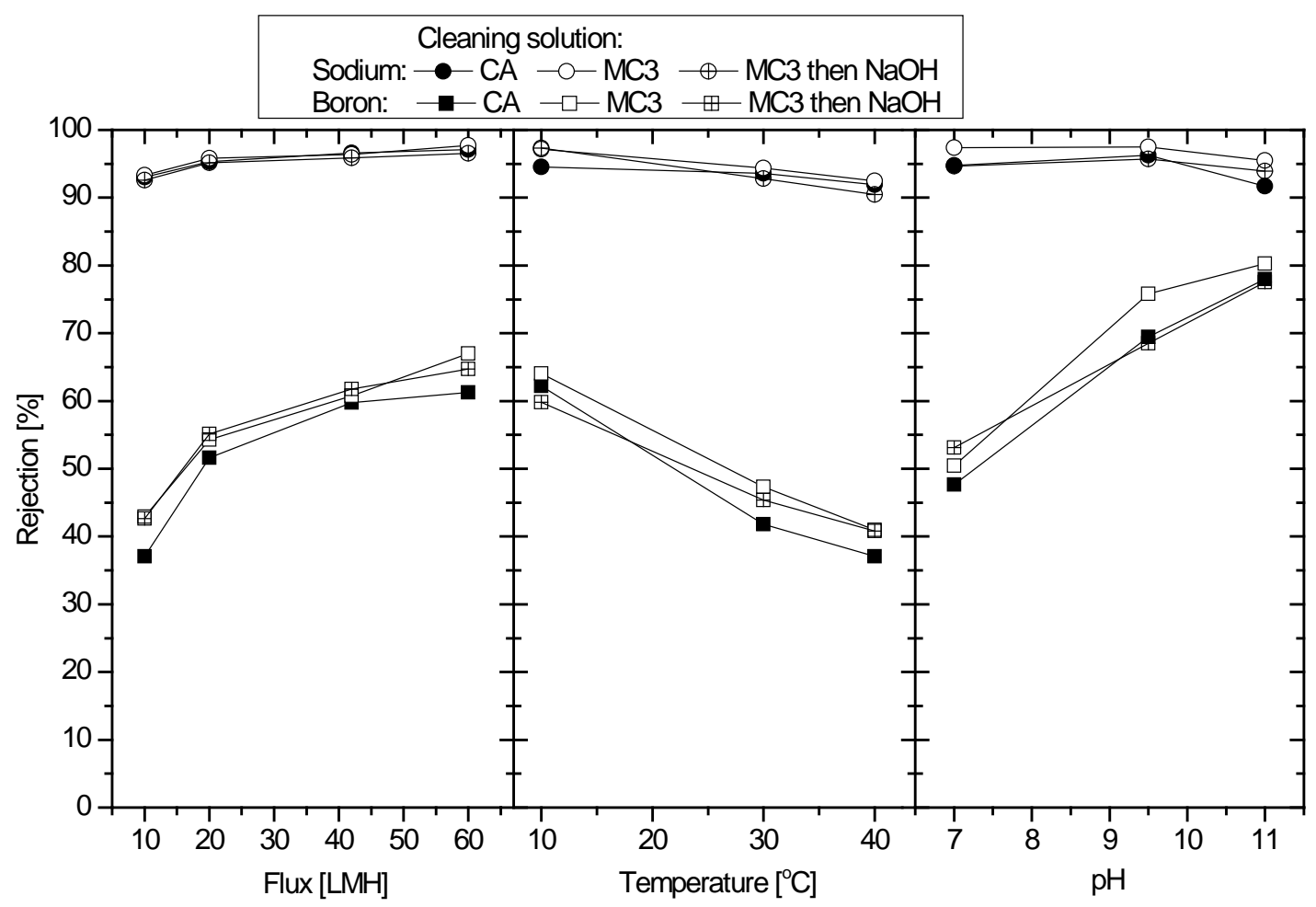

Fig. 10 Changes in boron and sodium rejections by the ESPA2 membrane after membrane cleaning with MC3 solution ( $\mathrm{pH} 3$ ) and MC3 solution followed by sodium hydroxide solution ( $\mathrm{pH} 11$ ). Unless otherwise stated, the testing conditions are: $\mathrm{pH}$ 8, feedwater contains $0.43 \mathrm{mM} \mathrm{B}(\mathrm{OH})_{3}, 10 \mathrm{mM} \mathrm{NaCl}, 1$ $\mathrm{mM} \mathrm{NaHCO} 3$, and $1 \mathrm{mM} \mathrm{CaCl}_{2}$; temperature $20^{\circ} \mathrm{C}$, permeate flux $20 \mathrm{LMH}$, cross-flow velocity $42 \mathrm{~cm} . \mathrm{s}^{-}$ 1

\section{Conclusion}

Membrane cleaning can substantially alter the hydrophobicity and water permeability of the RO membrane; however, its impacts on the rejections of boron and sodium are much less. This finding implies that water and solutes (boron and sodium) transport through RO membranes by different mechanisms. Different behaviours of boron rejection and sodium rejection were also observed in some cases (i.e. EDTA, SDS+EDTA, MC3), which underlined the difference between boron and sodium transport mechanisms through RO membranes. Although the presence of surfactant or chelating agent may cause some decreases in the rejections, solution $\mathrm{pH}$ was found to be the key factor responsible for the loss of membrane separation and surface properties. Strong acidic or caustic cleaning, respectively, would decrease or increase the water permeability. However, the impacts of solution $\mathrm{pH}$ on the water permeability could be reversed by applying a subsequent cleaning with opposite $\mathrm{pH}$ condition. On the other hand, the impacts of solution $\mathrm{pH}$ on boron and sodium rejections were irreversible in most cases. The results of this study imply that in order to minimise the impacts of chemical cleaning on the membrane performance, the cleaning solution either with or without the addition of surfactant and chelating agent should be used at less harsh $\mathrm{pH}$ conditions where possible. In addition, the strong impact of the cleaning solution on the water permeability suggests that a typical method to evaluate cleaning efficiency, which is based on the water permeability recovery, is of low reliability. A recovery in water permeability after membrane cleaning can be observed even when the fouling layer is not thoroughly removed, which may cause more severe fouling afterwards. 


\section{Acknowledgments}

The University of Wollongong is acknowledged for providing a PhD scholarship for Kha Tu.

\section{References}

Akin, O., Temelli, F. 2011. Probing the hydrophobicity of commercial reverse osmosis membranes produced by interfacial polymerization using contact angle, XPS, FTIR, FE-SEM and AFM. Desalination, 278, 387-396.

Al-Amoudi, A. 2013. Effect of chemical cleaning agents on virgin nanofiltration membrane as characterized by positron annihilation spectroscopy. Separation and Purification Technology, $110,51-56$.

Al-Amoudi, A., Lovitt, R.W. 2007. Fouling strategies and the cleaning system of NF membranes and factors affecting cleaning efficiency. Journal of Membrane Science, 303, 4-28.

Al-Amoudi, A., Williams, P., Al-Hobaib, A.S., Lovitt, R.W. 2008. Cleaning results of new and fouled nanofiltration membrane characterized by contact angle, updated DSPM, flux and salts rejection. Applied Surface Science, 254, 3983-3992.

Al-Amoudi, A., Williams, P., Mandale, S., Lovitt, R.W. 2007. Cleaning results of new and fouled nanofiltration membrane characterized by zeta potential and permeability. Separation and Purification Technology, 54, 234-240.

Ang, W.S., Lee, S., Elimelech, M. 2006. Chemical and physical aspects of cleaning of organicfouled reverse osmosis membranes. Journal of Membrane Science, 272, 198-210.

Ben Amar, N., Saidani, H., Palmeri, J., Deratani, A. 2009. Effect of temperature on the rejection of neutral and charged solutes by Desal 5 DK nanofiltration membrane. Desalination, 246, 294303.

Bernstein, R., Belfer, S., Freger, V. 2011. Toward improved boron removal in RO by membrane modification: Feasibility and challenges. Environmental Science and Technology, 45, 36133620.

Braghetta, A., DiGiano, F.A., Ball, W.P. 1997. Nanofiltration of natural organic matter: pH and ionic strength effects. Journal of Environmental Engineering-Asce, 123, 628-641.

Childress, A.E., Elimelech, M. 1996. Effect of solution chemistry on the surface charge of polymeric reverse osmosis and nanofiltration membranes. Journal of Membrane Science, 119, 253-268.

Childress, A.E., Elimelech, M. 2000. Relating nanofiltration membrane performance to membrane charge (electrokinetic) characteristics. Environmental Science and Technology, 34, 3710-3716.

Elimelech, M., Chen, W.H., Waypa, J.J. 1994. Measuring the zeta (electrokinetic) potential of reverse osmosis membranes by a streaming potential analyzer. Desalination, 95, 269-286.

Elimelech, M., Phillip, W.A. 2011. The future of seawater desalination: Energy, technology, and the environment. Science, 333, 712-717.

Fritzmann, C., Löwenberg, J., Wintgens, T., Melin, T. 2007. State-of-the-art of reverse osmosis desalination. Desalination, 216, 1-76.

Fujioka, T., Khan, S.J., McDonald, J.A., Roux, A., Poussade, Y., Drewes, J.E., Nghiem, L.D. 2013. $\mathrm{N}$-nitrosamine rejection by reverse osmosis: Effects of membrane exposure to chemical cleaning reagents. Desalination, 343, 60-66. 
Hoang, T., Stevens, G., Kentish, S. 2010. The effect of feed pH on the performance of a reverse osmosis membrane. Desalination, 261, 99-103.

Hung, P.V.X., Cho, S.-H., Moon, S.-H. 2009. Prediction of boron transport through seawater reverse osmosis membranes using solution-diffusion model. Desalination, 247, 33-44.

Hurwitz, G., Guillen, G.R., Hoek, E.M.V. 2010. Probing polyamide membrane surface charge, zeta potential, wettability, and hydrophilicity with contact angle measurements. Journal of Membrane Science, 349, 349-357.

Hydranautics. 2011. Foulants and cleaning procedures for composite polyamide RO membrane elements (ESPA, ESNA, CPA, LFC, NANO and SWC). TSB107.21.

Kang, G.-D., Gao, C.-J., Chen, W.-D., Jie, X.-M., Cao, Y.-M., Yuan, Q. 2007. Study on hypochlorite degradation of aromatic polyamide reverse osmosis membrane. Journal of Membrane Science, 300, 165-171.

Kaykioglu, G., Coban, A., Debik, E., Kayacan, B.B., Koyuncu, I. 2012. The evaluation of fouling effects in membrane process dealing with the biologically pre-treated textile effluents. Desalination and Water Treatment, 40, 254-259.

Kezia, K., Lee, J., Hill, A.J., Kentish, S.E. 2013. Convective transport of boron through a brackish water reverse osmosis membrane. Journal of Membrane Science, 445, 160-169.

Kim, C.K., Kim, J.H., Roh, I.J., Kim, J.J. 2000. The changes of membrane performance with polyamide molecular structure in the reverse osmosis process. Journal of Membrane Science, 165, 189-199.

Kimura, K., Hane, Y., Watanabe, Y., Amy, G., Ohkuma, N. 2004. Irreversible membrane fouling during ultrafiltration of surface water. Water Research, 38, 3431-3441.

Koseoglu, H., Kabay, N., Yüksel, M., Sarp, S., Arar, Ö., Kitis, M. 2008. Boron removal from seawater using high rejection SWRO membranes - impact of $\mathrm{pH}$, feed concentration, pressure, and cross-flow velocity. Desalination, 227, 253-263.

Li, Q., Elimelech, M. 2004. Organic fouling and chemical cleaning of nanofiltration membranes: Measurements and mechanisms. Environmental Science and Technology, 38, 4683-4693.

Li, Q., Xu, Z., Pinnau, I. 2007. Fouling of reverse osmosis membranes by biopolymers in wastewater secondary effluent: Role of membrane surface properties and initial permeate flux. Journal of Membrane Science, 290, 173-181.

Li, X., Li, J., Fu, X., Wickramasinghe, R., Chen, J. 2005. Chemical cleaning of PS ultrafilters fouled by the fermentation broth of glutamic acid. Separation and Purification Technology, 42, 181-187.

Liikanen, R., Yli-Kuivila, J., Laukkanen, R. 2002. Efficiency of various chemical cleanings for nanofiltration membrane fouled by conventionally-treated surface water. Journal of Membrane Science, 195, 265-276.

Madaeni, S.S., Mohamamdi, T., Kazemi Moghadam, M. 2001. Chemical cleaning of reverse osmosis membranes. Desalination, 134, 77-82.

Madaeni, S.S., Samieirad, S. 2010. Chemical cleaning of reverse osmosis membrane fouled by wastewater. Desalination, 257, 80-86.

Mänttäri, M., Pihlajamäki, A., Nyström, M. 2006. Effect of pH on hydrophilicity and charge and 
their effect on the filtration efficiency of NF membranes at different $\mathrm{pH}$. Journal of Membrane Science, 280, 311-320.

Schaep, J., Vandecasteele, C., Wahab, M.A., Richard, B.W. 2001. Modelling the retention of ionic components for different nanofiltration membranes. Separation and Purification Technology, 22-23, 169-179.

Simon, A., McDonald, J.A., Khan, S.J., Price, W.E., Nghiem, L.D. 2013a. Effects of caustic cleaning on pore size of nanofiltration membranes and their rejection of trace organic chemicals. Journal of Membrane Science, 447, 153-162.

Simon, A., Price, W.E., Nghiem, L.D. 2012. Effects of chemical cleaning on the nanofiltration of pharmaceutically active compounds (PhACs). Separation and Purification Technology, 88, 208215.

Simon, A., Price, W.E., Nghiem, L.D. 2013b. Influence of formulated chemical cleaning reagents on the surface properties and separation efficiency of nanofiltration membranes. Journal of Membrane Science, 432, 73-82.

Tang, C.Y., Kwon, Y.-N., Leckie, J.O. 2009. Effect of membrane chemistry and coating layer on physiochemical properties of thin film composite polyamide RO and NF membranes: II. Membrane physiochemical properties and their dependence on polyamide and coating layers. Desalination, 242, 168-182.

Teixeira, M.R., Rosa, M.J., Nyström, M. 2005. The role of membrane charge on nanofiltration performance. Journal of Membrane Science, 265, 160-166.

Tian, J.y., Chen, Z.l., Yang, Y.l., Liang, H., Nan, J., Li, G.b. 2010. Consecutive chemical cleaning of fouled PVC membrane using $\mathrm{NaOH}$ and ethanol during ultrafiltration of river water. Water Research, 44, 59-68.

Tu, K.L., Fujioka, T., Khan, S.J., Poussade, Y., Roux, A., Drewes, J.E., Chivas, A.R., Nghiem, L.D. 2013. Boron as a surrogate for N-nitrosodimethylamine rejection by reverse osmosis membranes in potable water reuse applications. Environmental Science \& Technology, 47, 6425-6430.

Tu, K.L., Nghiem, L.D., Chivas, A.R. 2011. Coupling effects of feed solution pH and ionic strength on the rejection of boron by NF/RO membranes. Chemical Engineering Journal, 168, 700-706.

Van der Bruggen, B., Hawrijk, I., Cornelissen, E., Vandecasteele, C. 2003. Direct nanofiltration of surface water using capillary membranes: comparison with flat sheet membranes. Separation and Purification Technology, 31, 193-201.

Weis, A., Bird, M.R., Nyström, M. 2003. The chemical cleaning of polymeric UF membranes fouled with spent sulphite liquor over multiple operational cycles. Journal of Membrane Science, 216, 67-79.

Wintgens, T., Melin, T., Schäfer, A., Khan, S., Muston, M., Bixio, D., Thoeye, C. 2005. The role of membrane processes in municipal wastewater reclamation and reuse. Desalination, 178, 1-11. 